\title{
CALL CENTER WORK FROM EMPLOYER AND EMPLOYEE PERSPECTIVE: TWO FIELD STUDIES FROM TURKISH BANKING SECTOR
}

\author{
GÖZDE YILMAZ \\ Assistant Professor, Kocaeli University Communication Faculty, \\ Journalism Department
}

\section{AŞKIN KESER}

Assistant Professor, Kocaeli University, Economics and Administrative Sciences Faculty, Labour Economics and Industrial Relations Department

\begin{abstract}
This paper consists two different studies' result. First study measured the burnout level and its relation with job satisfaction of call center employees. Results showed that burnout level explained \%50 of variance in job satisfaction. Second study documented the effect of electronic performance measurement on call productivity of employees. Monitoring increase the number of outgoing calls and decrease the duration of call which is a desired thing for employers.
\end{abstract}

For the majority of companies call centers become an integral part of customer relationship management. Parallel with this development, number of employees working in call centers continues to grow exponentially not only in developed countries, but also in developing countries like Turkey whose service sector and outsourcing operations of multinational companies pursues its consistent expansion. This creates a need towards understanding call center work. 
To our knowledge, there are studies which presented findings either from employee perspective (Bain and Taylor, 2000) or from employer perspective (Spkins et al., 1999). This study differentiates from these studies by incorporating employee and employer perspective to call center work with two different studies from Turkish banking sector.

First study represents the employee perspective regarding call center work by investigating burnout level of call center employees and its relation with job satisfaction. Results of this study revealed that "burnout" explained \% 50 of "job satisfaction" among call center employees. It remains unclear how employers benefitted from electronic performance monitoring and how call center employees reduce their workload which causes burnout among them under consistent electronic performance monitoring. For this reason, second study reflects the employer perspective by measuring the effect of electronic monitoring on call productivity of these employees. Lack of electronic monitoring caused a decrease in the number of outgoing calls and increased the duration of calls. These findings clearly show that call center employees attempted to decrease their high workload by increasing the duration of call and decreasing the number of outgoing calls. There is no doubt that employers benefit from the electronic monitoring by increasing the call productivity of call center agents while this workload cause job burnout among these employees.

Key Words: Electronic Mail, Mail, Organization, Communication

\section{INTRODUCTION}

Customer relationship management is crucial for today's costumer oriented companies, because of this necessity companies establish call centers with an increasing pace not only in developed countries but also in developing countries like Turkey ranging from financial services like banking to telecommunication sector. Multinational companies also increase the number of call centers in developing countries by outsourcing their call center work to countries with relatively low wages.

As the number of employees working in call center increases in Turkey, so do the need to study call center work from two side-employee and employer. We think that adopting etiher employer perspective or employee perspective could be one-sided. The need to study call center's employees' burnout level-job satisfaction relation and effect of electronic performance monitoring (EPM) on call productivity is crucial. But in developing countries, call center employees' working condition, and in this context their burnout level and performance has failed to become a subject of debate among researchers and academicians. 
This study tries to fill this gap by providing emprical data regarding burnout-job satisfaction relation and effect of electronic monitoring on call productivity of call agents.

\section{Employees in Call Centers and Nature of Call Center Job}

Call centers can be defined as physical or virtual operations in which a managed group of people spend most of their time doing business by telephone, usually working in a computer-automated (Merchants' Group, 1998; Bagnara and Marti, 2001; 223) in-house department or in an outsourced operation center which organizes communication with customers (Zapf,et al., 2003, 312). Bain and his colleages cited that call centers internationally showed the most dynamic area of growth in white-collar employment $(2001,3)$.

Call center jobs characterized by high degree of computerization and standardization of work. Because of these features, this type of work usually depicted as an unskilled work with high time pressure and dehumanisation of work (Russell). That's why some authors (Knights, McCabe, 1998) describe it as an expression of "Taylorism" (Taylor and Pain, 1999). Consistent and tight technological surveillance and repetetive work cause stress which later result in job dissatisfaction among these employees.

Number of studies provide support for depicting call center work as a stressful job (Taylor and Bain, 1999, Wallece, Eagleson, and Waldersee, 2000, Baumgart et. Al., 2002, Deery, Iverson and Walsh, 2002, Holman 2002,2003) because of low task variety, i.e., repetition of the same task over extended periods), low task complexity (i.e., only few necessities of own decisions, Frese and Zapf, 1994), and low utilization of qualification (knowledge, skills, and abilities) and low levels of job control (Grebner et al., 2003, s.342, Lewig and Dollard, 2003, 367). This type of work psychologically wear out call center employees. Also more psychosomatic complaints seen in call centers. (Zapf, 2003, s.313). 


\section{Job Burnout and Job Satisfaction}

Strategic objectives of call centers listed as: ensuring a low response time; continually improving the quantity and quality of costumer services; reduction of cost. To achieve these strategic objectives, call centers monitor their employees performance electronically and increase their workload by determining high performance standarts which cause burnout among employees.

Job burnout means job dissatisfaction for call center employees. Workers feel unhappy about themselves and dissatisfied with their accomplishments on the job (Maslach and Jackson, 1981, 99). In this emotional position workers experience loneliness and helplessness. This feeling appears to be a important factor in job turnover, absenteeism and tend to give up work. So burnout syndrome has very serious consequences both for employees and employers.

'Burnout' defined as: a negative psychological experience that is a reaction of people to job-related stress (Sari, 2004, 292). Burnout is characterized by fatigue, depression, hopelessness and lack of enthusiasm. (Sockel, et al.,).

The conditions that cause burnout in workplace are documented as "Lack of control", "Work overload", "Role Conflict or Ambiguity" and "Individual Factors" in literature.

In a typical call center, employees have to deal with too many telephone calls at a pre-determined time interval, with constant crises (Cedoline, 1982). Lack of control and time pressure is typical character of call center jobs, so this situation causes stress and burnout syndrome.

In the first part of this study, relation between burnout and job satisfaction tried to be revealed. The literature reviewed showed that burnout result in job dissatisfaction. So it is hypothesized that: burnout among call center agents result in job dissatisfaction. 


\section{METHOD}

\section{Sample}

150 call center agents working for a Turkish commercial bank participated the first part of the study. This number represents the whole workers working in this call center. Questionnaire was distributed to agents and 110 survey were returned. Because of excessive unanswered statements, 101 out of 110 questionnaries were used for data analysis. Response rate was $\% 75,9$.

When the demographic dispersion of the sample investigated, it can be seen that $\% 78$ of the employees $(n=79)$ are woman and only $\% 21,8$ of them are man. This dispersion of gender clearly shows the feminisation of call center work.

When the educational qualification of the sample investigated $\% 89$ are university graduates. This shows that call center agents are highly educated and seem to offer employment opportunities to university graduates.

\section{Instruments}

Scales used in this study consisted questions from the Maslach Burnout Inventory and the Job satisfaction.

Respondents were asked to answer 22 items from Maslach Burnout Inventory developed by Maslach and Jackson (1986). Three subscales measuring emotional exhaustion, personnel accomplishment and depersonalization used in the context of this study. The emotional exhaustion subscale consisted of nine items which describes unfeelings emotionally over extended and exhausted by one's work. The five items on depersonalization subscale describe unfeeling and impersonal responses to co-workers or recipients of services. The Personal accomplishment subscale consists of eight items, describing feelings of competence and success about one's achievements.

A five-point response scale was used, (Maslach and Jackson, 1986) ranges from 1 (never) to 5 -(always). The higher mean scores of the Emotional exhaustion and Depersonalization subscales correspond to greater degrees of burnout. Cronbach's alpha for this scale was .8517 . 
Job satisfaction. Job satisfaction of employees was measured using a 5 item scale from Brayfield and Rothe (1951). Respondents were asked to indicate how often each statement occurs. Responses were made on a five-point scale ranging from $1=$ "less than once per month or never" to $5=$ "several times per day".

Data showed that scales used are reliable (Cronbach $\alpha$ for Burnout Scale $=, 8517$ and Cronbach $\alpha$ for Job satisfaction= ,9038).

\section{Results}

When the mean score for burnout investigated, it can be seen that it was not too high among call center employees.

Table-1 Burnout Among Age Groups, Gender and Education

\begin{tabular}{|l|lll|}
\hline & \multicolumn{3}{|c|}{ Job Burnout } \\
\hline Age Groups & $\mathrm{n}$ & Mean & Std. Dev. \\
\hline $20-24$ & 38 & 1,72 & 0,49 \\
$25-29$ & 63 & 1,85 & 0,50 \\
\hline Gender & $\mathrm{n}$ & Mean & Std. Dev. \\
\hline Woman & 79 & 1,84 & 0,56 \\
Man & 22 & 1,67 & 0,10 \\
\hline Education & $\mathrm{n}$ & Mean & Std. Dev. \\
\hline Undergraduate & 38 & 1,82 & 0,48 \\
Graduate & 63 & 1,31 & 0,49 \\
High School & 38 & 1,93 & 0,74 \\
\hline
\end{tabular}


Table 2 -Independent $t$ test and ANOVA Results

\begin{tabular}{|l|l|l|l|}
\hline & \multicolumn{3}{|c|}{ Job Burnout } \\
\hline & $\mathrm{F}$ & $\mathrm{p}$ & \\
\hline Age Groups & 1,68 & 0,19 & \\
\hline Gender & 1,86 & 0,17 & \\
\hline Educational Level & 3,2 & 0,45 & \\
\hline
\end{tabular}

${ }^{*} p<0,05$

According to independent $t$ test and ANOVA results, no difference can be found among age groups, gender and educational level.

For testing the effect of burnout level on job satisfaction, a regression analysis was done. The results of the regression analysis are presented in Tables 3 and 4.

\section{Table-3 Model Summary}

\begin{tabular}{|c|c|c|c|c|}
\hline Model & $\mathrm{R}$ & $\mathrm{R}$ Square & Adjusted R Square & Std. Error of the Estimate \\
\hline 1 &, 716 &, 513 &, 508 &, 57126 \\
\hline
\end{tabular}

a Predictors: (Constant), BURNOUT

Table-4 Coefficients

\begin{tabular}{|r|r|r|r|r|c|c|}
\hline & & $\begin{array}{r}\text { Unstandardized } \\
\text { Coefficients }\end{array}$ & & $\begin{array}{r}\text { Standardized } \\
\text { Coefficients }\end{array}$ & $\mathrm{t}$ & Sig. \\
\hline Model & $\mathrm{B}$ & $\begin{array}{r}\text { Std. } \\
\text { Error }\end{array}$ & Beta & & \\
\hline 1 & (Constant) & 4,965 &, 226 & & 21,979 &, 000 \\
\hline & Burnout & $-1,184$ &, 122 &,- 716 & $-9,736$ &, 000 \\
\hline
\end{tabular}


According to results, "burnout" explains \% 50,8 of "job satisfaction". Our hypothesis is accepted. These results indicated that "burnout" among call center employees is an important variable which explains "job satisfaction".

Call center employees have a strategic importance for companies because they try to satisfy various consumers need. So call center employees could be classified as front-line workers for organizations serving more service on phone. Because of the importance of these employees, their burnout level should be reduced if retention and customer satisfaction desired.

\section{Study- Effect of Electronic Monitoring on Call Productivity of Agents and Ways of Escaping from High Workload- Employer Perspective}

First study revealed that as the burnout increases so do the job dissatisfaction of call center employees. Second study looked at call center work from an another perspective -employer. Monitoring employee performance against pre-defined standarts is crucial for the survival and of organizations under today's fierce competition. Because of this necessity employers deploy electronic performance monitoring in workplaces. Electronic monitoring of employees can help managers enhance productivity (Aiello, 1993; Griffith, 1993), maintain production standards, attain knowledge on how employee time was being deployed (Bain et al., Bain \& Baldry 1992)) and plan the future personel need. As a natural result, employers are among the leading proponents of electronic monitoring in any kind of work especially in labour intensive industries.

Proponents of monitoring mentioned the positive effects of monitoring for employees like producing more objective and timely performance appraisals and improved performance feedback (Angel, 1989; Henriques, 1986a, 1986b; Chalykoff \& Kochan, 1989 cited in Alder, 2001; 323). Electronic performance monitoring (EPM) affects workers' behavior. Aiello and Kolb (1995) had documented positive effects of monitoring on productive behavior of employees by the help of social facilitation theory.

Call centres are among the leading industries using EPM for producing detailed data on pre-defined performance measures. EPM permits supervisors to obtain valuable performance information that can also be 
used for employee development (Alder, 2001; 323) not only for punishment and performance based pay. Call centres use EPM to increase quantity and quality of call. In the context of the second study, quantative dimension of employee performance reported by Automatic Call Distribution (ACD) system investigated. In Turkey, employers usually base their assessment on quantative measures. So our second study which reflect the employer perspective based on quantative measures.

For research purposes, measures of performance generated by electronic monitoring devices are indicated. Measures captured by EPM devices are average number of minutes per call, number of calls received, handled and lost, average number of rings or seconds before an answer, and call abandon rate (Ables, 2002).

We will test the effect of monitoring on employee performance moving from the performance measures generated by Automatic Call Distribution system.

\section{METHOD}

\section{Subjects}

The study covered call center agents $(\mathrm{N}=47)$ employed by a middle sized Turkish commercial bank. All of the agents take inbound calls and make outbound contacts. The average age of the agents was 24,1 years, and $71 \%$ percent were female. Feminizations of call center jobs were verified by the second study data too. Average tenure of the subjects was 1,63 years $(S D=1,01)$.

\section{Data Collection Procedure}

In this study, two controlled situation created. In the first controlled situation, employees were aware that the electronic monitoring devices is on as usual. Employees clearly knowed that their performance monitored by ACD. In the other situation, they were told that the electronic monitoring devices are not in charge because of an operation failure but in fact working regularly. Employees were monitored in each situation for 10 days. During these two different time period, data 
regarding the performance of each employee collected systematically by the system. ACD produces statistics for each employee.

Both inbound and outbound calls had taken into consideration in this study. This data included the number of calls received and number of outcalls for each call center agent.

\section{Results}

According to the results, there was no significant difference in the number of inbound calls in two different period but there was significant difference in number of outbound calls and average time per call. Thus, call center agents could not get less call in non-monitoring environment but they increased the time through the call although they should do their work as fast as possible. Also they did not make more outbound calls in the non-monitored condition. There was no difference in number of incoming calls. We bind this result to ACD, because ACD is an automated system which routes calls to available agent without any time waste.

While average outbound call was $1.038,1(S D=672,1)$ in monitored condition; it decreased to $768,1(S D=429,7)$ in non-monitored condition. On the other hand, under electronic monitoring average time per call (including both outbound and inbound calls), which represents the amount of time an employee handles a "case" was 221,8 seconds $(S D=119,1 \mathrm{sec})$ and when the employees thought that electronic monitoring is off average call time reached to 235,8 seconds $(S D=89,3)$. Proponents of this statistic argue that the lower the average-call-time, the higher the productivity since long average-speed-of-answers increase unanswered customers. Thus, it can be concluded that monitoring affects the productivity of the call center agent in terms of outbound calls and average time per call. 
Table 5: ACD Statistics

\begin{tabular}{|c|c|c|c|c|c|c|}
\hline \multirow{3}{*}{$\begin{array}{l}\mathrm{N}=47 \\
\text { Number of Inbound } \\
\text { Calls }\end{array}$} & \multicolumn{2}{|c|}{$\begin{array}{l}\text { Monitored } \\
\text { Condition }\end{array}$} & \multicolumn{2}{|c|}{$\begin{array}{l}\text { Non-Monitored } \\
\text { Condition }\end{array}$} & \multicolumn{2}{|c|}{$\begin{array}{l}\text { Paired } \quad z \\
\text { Test }\end{array}$} \\
\hline & $\mathrm{M}$ & SD & $\mathrm{M}$ & SD & $Z$ & $P$ \\
\hline & 638,6 & 230,1 & 651,8 & 255,4 & $\overline{0}, 32$ & 0,75 \\
\hline $\begin{array}{l}\text { Number } \\
\text { Outbound Calls }\end{array}$ & $1.038,6$ & 672,1 & 768,1 & 429,7 & 3,17 & $0,00^{\star \star}$ \\
\hline $\begin{array}{l}\text { Average Time Per } \\
\text { Call }(\mathrm{sec})\end{array}$ & 212,8 & 119,1 & 235,8 & 89,3 & $-\overline{2}$ & $0,03^{*}$ \\
\hline
\end{tabular}

${ }^{*} p<0,05{ }^{* *} p<0,01$

Call center are labor intensive operation for employers and beacuse of high personnel employment rate compared to other departments and lack of replacing machines by humans make employers to see call centers as cost center (Slater, 1999, Weitzman, 2000). Evident in the second study results, electornic performance monitoring increase the call productivity of emloyees by increasing the number of outbound calls and by decreasing the average time time per call. Pervasiveness of ACD systems which is an integrated part of call center's technological infrastructure leads to a quantative increase in productivity. Further studies could invesitigate quantative and quality dimension of employee performance for presenting the whole picture.

\section{CONCLUSION}

Number of employees working in call centers increasing rapidly in developed and developing countries Call center employment figures in develoing countries represent a different picture. Because not only local companies establish call centers but also multinational companies prefer developing countries because of low wages and high umploymnet among white-collar workerd. Turkey is one these countries with increasing employment figures in call centers. The purpose of the above-mentioned studies was to examine call center work from employer and employee perspective which is absent in Turkey. Workload level explain \%35 of burnout among these employees which means that for employers workload must be concern for retention of call center employees. Looking from the employer perspective, electronic 
monitoring increase the call productivity of agents which is highly desirable among employers. But use of electronic monitoring leads to starndartization and routineization of call center work which in turn cause a loss of control on work.

\section{REFERENCES}

Aiello, John R. and Carol M. Svec(April 1993), "Computer Monitoring of Work Performance: Extending the Social Facilitation Framework to Electronic Presence", Journal of Applied Social Psychology, 23(7) pp. 537-548.

Aiello, J. R. and Kolb, K. J. (1995), "Electronic Performance Monitoring and Social Context: Impact on Productivity and Stres", Journal of Applied Psychology, 80, pp.339-353.

Alder, G. S. and Tompkins, P. K. (1997), "Electronic Performance Monitoring: An Organizational Justice and Concertive Control Perspective", Management Communication Quarterly, 10, pp. 259 - 288.

Bakker, Arnold B., Demerouti, Evangalia and Schaufeli, Wilmar B., (2003) "Dual Process at work in a call center:An application of the job demandsresources model" European Journal of Work and Organizational Psychology, Vol:12 No:4

Brayfield, A.H., Rothe, H.F., (1951) "An index of Job Satisfaction", Journal of Applied Psychology, Vol:35

Cedoline, Anthony J.; (1982) Excerpts from Job Burnout: Symptoms, Causes, and Survival Skills, Columbia University Press

Chalykoff, J. and Kochan, T. A. (1989), "Computer-Aided Monitoring: Its Influence on Employee Satisfaction and Turnover", Personnel Psychology, 42, pp. $807-834$.

Chalykoff, J. and Nitin Nohria (1998), "Office Productivity in Computerized Settings: The Role of Machine Statistics, Performance Feedback and Job Experience", Journal of Comparative International Management, Vol:1,No:1, June.

Dieter Zapf, Amela Isic, Myriam Bechtoldt and Patricia Blau, (2003) "What is typical for call center jobs? Job characteristics, and service interactions in 
different call centers", European Journal of Work and Organizational Psychology, Vol: 12 No: 4

Grant, R. and C. Higgins (1989), "Monitoring Service Workers Via Computer: The Effects on Employees' Productivity and Service", National Productivity Review, 8, pp.101-112.

Grebner, Simone, Semer, Norbert K., Faso, Luca Lo, Gut, Stephan Gut, Kälin, Wolfgangand, Elfering, Achim; (2003) "Working conditions, well-being, and jobrelated attitudes among call center agents", European Journal of Work and Organizational Psychology, Vol:12 No:4.

Irving, R.H., Higgins, C.A. and Safayeni, F.R. (1986), Computerized Monitoring Systems: Use and Abuse, Communications of the ACM, 29, pp.794-801.

Maslach, Christina; (2003) "Job Burnout: New Directions in Research and Intervention", Current Directions in Psychological Sciences, Vol: 12, No: 5, October

Maslach, Christina, Jackson, Susan E.; (1981) "The measurement of experienced burnout", Journal of Occupational Behaviour, Vol: 2

Mishra, Jitendra M. and Suzanne M. Crampton (1998), "Employee Monitoring: Privacy In The Workplace? S.A.M", Advanced Management Journal, Vol. 63, No.3, Summer, pp. 4-14.

Sebastiano Bagnara, Patrizia Marti; (2001) "Human work in call centers: a challenge for cognitive ergonomics", Theoritical Issues in Ergonomics Science, Vol: 2, No: 3

Simone Grebner, Nobert K.Semmer, Luca Lo Faso, Wolfang Kalin and Achim Elfering, (2003) "Working conditions, well-being, and job-related attitudes among call center agents", European Journal of Work and Organizational Psychology, Vol: 12 No: 4

Sockel, Hy, Chen, Kauanchin, Chen, and Kroeger, James W.; "Technological Adoption to Combat Burnout", [http://isedj.org/isecon/2001/15b/ISECON.2001.Sockel.pdf]

Spector, P. E., \& Jex, S. M., (1998) "Development of Four Self-Report Measures of Job Stressors and Strain: Interpersonal Conflict at Work Scale, Organizational Constraints Scale, Quantitative Workload Inventory, and 
Physical Symptoms Inventory" Journal of Occupational Health Psychology, Vol:3

Stanton, J.M. \& E.M. Weiss (2000), "Electronic Monitoring in Their Own Words: An Exploratory Study of Employees' Experiences With New Types of Surveillance", Computers in Human Behavior, Vol:16

Stephen J. Frenkel, May Tam, Marek Korczynski and Karen Shire, (1998), "Beyond Bureaucracy? Work organization in call centers", The International Journal of Human Resource Management, Vol: 9, No: 6

Stoney, Alder G. (2001), "Employee Reactions to Electronic Performance Monitoring:A Consequence of Organizational Culture", The Journal of High Technology Management Research, Vol:12

Taylor, P., and Bain, P.; (1999) "An assembly line in the head: Work and employee relations in the call center", Industrial Relations Journal, Vol: 30 Issue: 2

Tuten, Tracy L. and Presha E. Neidermeyer (2004), "Performance, Satisfaction and Turnover in Call Centers: The Effects of Stress and Optimism", Journal of Business Research, Vol. 57, Issue 1

Udo Konradt, Guido Hertel, Renate Schmook, (2003) "Quality of management by objectives, task-related stressors, and non-task-related stressors as predictors of stress and job satisfaction among teleworkers", European Journal of Work and Organizational Psychology, Vol:12 No:1 